\title{
Long-term renal function and mortality after radical cystectomy and ileal conduit formation.
}

Julio Chevarria ( $\square$ jl.chevarria@gmail.com )

Beaumont Hospital https://orcid.org/0000-0002-4641-6568

Chaudhry A. Ebad

Beaumont Hospital

Mairead Hamill

Beaumont Hospital

Catalin Constandache

Beaumont Hospital

Cliona Cowhig

Beaumont Hospital

Hazel O'Shea

Beaumont Hospital

Sandra Deady

National Cancer Registry

Dilly M Little

Beaumont Hospital

Peter J. Conlon

Beaumont Hospital

Research article

Keywords: Dialysis, chronic kidney disease, Bladder cancer, Cystectomy

Posted Date: August 18th, 2020

DOI: https://doi.org/10.21203/rs.3.rs-57335/v1

License: (c) (i) This work is licensed under a Creative Commons Attribution 4.0 International License.

Read Full License 


\section{Abstract \\ Background.}

Treatment for bladder cancer includes radical cystectomy (RC) and urinary diversion, $\mathrm{RC}$ is associated with long-term morbidity, renal function deterioration and mortality. Our aim was to identify risk factors associated with postoperative long-term renal function decline and mortality.

\section{Methods.}

Retrospective study in patients with RC and urinary diversion in Beaumont Hospital from 1996 to 2016. We include patients who had assessment for at least two years post procedure and confirmed live status. We assessed the estimated glomerular filtration rate (eGFR) preoperatively, at first and second year, renal function decline $>10 \mathrm{ml} / \mathrm{min} / 1.73 \mathrm{~m}^{2}$, start dialysis and mortality. Logistic regression analyses were applied to assess risk factors associated, a significant $p$-value $<0.05$ was considered.

\section{Results.}

We included 264 patients, with median age 68.3 years, $73,7 \%$ males, main diagnose was bladder cancer 93.3\%, TNM stages were grouped in $T \geq 275.9 \%, N \geq 147.6 \%$ and $M 128 \%$. The median eGFR preoperative was $65.8 \mathrm{ml} / \mathrm{min} / 1.73 \mathrm{~m}^{2}$ and after 2 years $58.2 \mathrm{ml} / \mathrm{min} / 1.73 \mathrm{~m}^{2}$ (p:0.009), $5.6 \%$ required chronic dialysis and $32.8 \%$ had a decrease $>10 \mathrm{ml} / \mathrm{min} / 1.73 \mathrm{~m}^{2}$. Risk factors associated with ESKD included age (HR:1.13, Cl95\% 1.05-1.22), preoperative eGFR (HR:1.04, Cl95\% 1.01-1.07). Overall mortality was $43.2 \%, 75.9 \%$ at 5 and 10 years respectively, risk factors were age (HR:1.1, Cl95\% 1.041.18), preoperative eGFR (HR:1.03, Cl95\% 1.01-1.06) and male gender (HR:14.8, Cl95\% 1.1-192).

\section{Conclusions.}

Patients with RC have risk of progressive renal function deterioration and high mortality and the main risk factors associated were age, sex, and preoperative eGFR. Regular monitoring of renal function will permit early diagnosis and treatment.

\section{Background}

The international gold standard treatment for muscle invasive bladder cancer with curative intent is a multimodal approach involving radical cystectomy (RC), resection of regional lymph nodes, urinary diversion and neo-adjuvant chemotherapy (1). The two most commonly used procedures for urinary diversion are ileal conduit diversion (ICD) and orthotopic neobladder formation (2). Although surgery itself is associated with significant perioperative morbidity and mortality, the 5-year relative survival rate 
has improved greatly in recent years $(3,4)$. It has resulted in consideration of the long-term impact of surgery on morbidity, quality of life and it has been shown that patients after RC are at increased lifetime risk of deterioration in renal function and progression to chronic kidney disease (3-7).

Chronic kidney disease itself is an independent risk factor for all-cause mortality, and cardiovascular events $(8,9)$. Multiple factors have been implicated in the deterioration of renal function postoperatively, these can be divided into patient factors such as advancing age, central obesity, diabetes mellitus, hypertension and preoperative renal impairment, and iatrogenic factors such as use nephrotoxic chemotherapy, perioperative blood loss, post-operative urinary tract infection or obstruction (10-16). The trajectory of the deterioration of renal function is thought to be biphasic: an accelerated decline is seen in the first two postoperative years with a moderate loss occurring gradually over later years (12).

In this study, we analysed data from all patients who underwent radical cystectomy in our hospital, a tertiary referral centre for urological cancer, from 1996 to 2016. The aim was to identify potential risk factors associated with postoperative and long-term renal function decline and mortality.

\section{Methods}

Following institutional review board approval, a retrospective study was conducted of patients undergoing radical cystectomy from January 1996 to December 2016. We identified a total of 338 consecutive adult patients underwent radical cystectomy and urinary diversion attended in Beaumont Hospital Urology department. We excluded patients with partial cystectomy $(n=33)$, without urinary diversion due to dialysis $(n=2)$ and patients whose analysis data were unavailable or incomplete $(n=$ 39). We included 264 patients who had undergone total radical cystectomy and ileal conduit diversion or cutaneous ureterostomy, patients who had on going assessment for at least two years post procedure, with clinical and laboratory. We confirmed the live status and mortality with the National Cancer Centre Office database, which is maintained prospectively.

The preoperative factors analysed were age at RC, gender, smoking history, concomitant comorbidity (DM and $\mathrm{HTN}$ ), body mass index (BMI), preoperative renal function, type of surgical technique, indication for surgery and tumour stage. The main outcomes were mortality, renal function deterioration and end stage kidney disease (ESKD). We assessed kidney function using the CKD-EPI equation (17). Deterioration in renal function was defined as clinically relevant if there was a $>10 \mathrm{ml} / \mathrm{min} / 1.73 \mathrm{~m}^{2}$ decrease in eGFR at 2 years compared to the baseline value before surgery. This threshold was chosen because a rate of deterioration as it has been shown to be superior to $5 \mathrm{ml} / \mathrm{min}$ per year decline is considered clinically significant (14). 


\section{Data analysis and statistical methods.}

Continuous variables are shown using summary statistics and categorical variables as frequencies. We performed exploratory analyses for categorical variables using Fisher's exact or chi square test and continuous with student $T$ test. The incidence of ESKD requiring dialysis was estimated using the KaplanMeier method and compared log-rank test. For patients who had not experienced the event of interest were censored at the time of the last urologic follow-up or death not owing to events of interest.

Multivariate logistic regression was applied to identify independent risk factors and reported as hazard ratios (HR) with $95 \% \mathrm{Cl}$. The covariates were selected among baseline variables and compared in a bivariable model, with patient outcomes mortality and ESKD. We selected variables to be included in regression models if the $p$-value was $<0.10$. We included age, sex and eGFR perioperative in all models. To achieve model parsimony and stability, we analyse all possible models and select the best model with the criteria a change $<10 \%$ in the full model B coefficient, selection procedure was applied with the dropout criterion $\mathrm{P}>0.1$. All probabilities were two sided, and a $\mathrm{p}$-value $<0.05$ was considered significant. All analyses were performed using SPSS 19 (IBM-California).

\section{Results}

We evaluated 264 patients, the clinic pathological characteristics and distributions are shown in Table 1. The median age was 68.3 years (IQR 13.7), weight $74.0 \mathrm{~kg}$ (SD 20), height $170 \mathrm{~cm}$ (SD 11), BMI 25.2 $\mathrm{km} / \mathrm{m} 2$ (SD 6.3). 73,7\% were males, $14,7 \%$ had diabetes, $44.2 \% \mathrm{HTN}, 29.3 \mathrm{IHD}, 9 \% \mathrm{CVA}, 18.5 \% \mathrm{PVD}, 30 \%$ were smoker and 43.9 ex-smoker, the main indication for surgery was bladder cancer $93.3 \%$, other $6.7 \%$ (haemorrhagic, shrunken bladder, neurogenic), the surgical techniques were Wallace $29.8 \%$, Bricker $64 \%$. The main postoperative complications were pyelonephritis $6.4 \%$, recurrent UTI $19.1 \%$, Ureteral stricture $7.9 \%$, lithiasis $4.8 \%, 12.7 \%$ required admission in ICU, $14.3 \%$ had surgical infection, sepsis $23.4 \%$, a total of $75.9 \%$ died, and $5.3 \%$ started dialysis. Overall pathological $\mathrm{T}, \mathrm{N}$ and $\mathrm{M}$ stage were grouped in $\mathrm{T} \geq$ stage $2(75.9 \%), \mathrm{N} \geq$ stage $1(47.6 \%)$ and $\mathrm{M} 1$ stage (28\%) (Table 1$)$.

The median eGFR pre operative was $65.8 \mathrm{ml} / \mathrm{min} / 1.73 \mathrm{~m}^{2}$ (IQR 48.5 to 81.5 ), and after 2 years decreased to $58.2 \mathrm{ml} / \mathrm{min} / 1.73 \mathrm{~m}^{2}$ (IQR 45.3 to 79.2 ), the difference being statistically significant (p: 0.009 ) (Graphic 01). Fourteen patients (5.6\%) had a new CKD stage $V$ and required chronic dialysis, 2 of them require dialysis immediately, the time to start dialysis 3.3 years (IQR 8.0). $41.3 \%$ of patients had moderate to severe CKD (stage III-V) pre surgery; after 2 years postoperatively this percentage increased to $53.9 \%$. A decrease in eGFR greater than $10 \mathrm{ml} / \mathrm{min} / 1.73 \mathrm{~m}^{2}$ at two years was present in $32.8 \%$. It is noteworthy that $63.3 \%$ of patients had a reduction in their eGFR after 2 years, although $36.7 \%$ maintained stable kidney function or mild increase in their eGFR. 
In bivariable analysis, independent risk factors for ESKD and commencement of dialysis were age (HR 1.64, Cl95\% 1.02 - 1.12), stage T $\geq 2$ (HR 3.4, CI95\% 1.2 - 10.3) and the eGFR pre-operatively (HR 1.02, C195\% 1.0 - 1.05) (Table 02). The Kaplan-Meier curve showed that the cumulative incidence of ESKD at 5-years were 5.6\% (Graphic 02). On logistic regression analysis, both eGFR preoperatively (HR 1.04, CI95\% 1.01-1.07) and age (HR 1.13, CI95\% 1.05-1.22), were significant factors in predicting ESKD, gender and tumour stage were not significant (Table 03).

Survival time after surgery in patients who died was 4.6 years. Overall mortality was $21.4 \%, 43.2 \%, 75.9 \%$ at 1, 5 and 10 years, respectively. In bivariable analyses, independent risk factors for mortality was age (HR 0.94, Cl95\% 0.92-0.97), male sex (HR 2.0, Cl95\% 1.2-3.5), bladder cancer (HR 10.1, Cl95\% 3.4-30.2), and stage $T \geq 2$ (HR 2.3, Cl95\% 1.3-4.2). In logistic regression analysis, older patient age (HR 1.1, CI95\% 1.04-1.18), preoperative eGFR (HR 1.03, CI95\% 1.01-1.06) and male gender (HR 14.8, CI95\% 1.1-192) were independently associated with increase in mortality (Table 04).

\section{Discussion}

The demographics of our cohort are similar to that of previous studies in terms of age, gender (10-14, 18-20), mean follow up period 7.5 to 10 years $(5,11-14,19,20)$, prevalence of hypertension and diabetes $(10-12,14,19,20)$, indication for RC bladder cancer $(10-12,14,18,19)$, with stages $T \geq 2$ from 63 to $78 \%(12,19,20)$, therefore, our study is comparable to these previous reports.

We found that the majority experienced a decrease in renal function during long-term follow up. The initial eGFR in our cohort was $65.8 \mathrm{ml} / \mathrm{min} / 1.73 \mathrm{~m}^{2}$, which is similar to previous reports $(10,12-14,19)$ with initial eGFR ranging from 65 to $69.7 \mathrm{ml} / \mathrm{min}$, with the exception of Samuel et al, that show an eGFR of 77, most likely because of a younger population group. The eGFR after two years was $55 \mathrm{ml} / \mathrm{min}$, again similar to previous reports with ranges from 55 to $59(11-14,19)$, being comparable. $62.8 \%$ of patients had a decline of their kidney function during follow up, and $32.8 \%$ of patients had a decrease of $>10 \mathrm{ml} / \mathrm{min} / 1.73 \mathrm{~m} 2$ at 2 years. Previous studies have shown a high prevalence $70 \%(11,20)$ at 10 years, and $49 \%$ at 5 years (11), however there are reports with a lower prevalence 34 to $51 \%$ (12-15). The difference in the prevalence through the different studies could be explained due to different definitions to categorize the decline in kidney function, as well as different follow up times, and different methods to measure the GFR.

There is a predictable decline in the kidney function related to aging; the annual age-related decline in eGFR from age 30 years is believed to be $\pm 1 \mathrm{~mL} / \mathrm{min} / 1.73 \mathrm{~m}^{2}$ in healthy population (21-23), this GFR declines by about $8-10 \mathrm{ml} / \mathrm{min} / 1.73 \mathrm{~m}^{2}$ per decade $(24,25)$, by other side, a linear decline in eGFR over time is often observed (26) in patients with diabetes or HTN, the decline in persons with diabetes range from $\pm 2-3 \mathrm{~mL} / \mathrm{min} / 1.73 \mathrm{~m}^{2}$ per year (27). In patients with RC and ICD, previous reports have used 
definitions such as a decrease of $1 \mathrm{ml} / \mathrm{min} /$ year $(5,11,12)$ in a time period of 5 to 10 years, a decrease of $>25 \%(15,19)$ in eGFR from baseline, or a decline $>10 \%$ in eGFR $(11,14)$. The definition of clinical significant deterioration in renal function in our study was a decrease of $>10 \mathrm{ml} / \mathrm{min} / 1.73 \mathrm{~m}^{2}$ in the first two years. This was selected because the majority of the observed decline in kidney function in previous studies happens in the first 2 years $(12,19)$. This represents the period for major risk for kidney function deterioration, which is likely associated with RC and of clinical significance.

A further difference relates to the method used to measure the kidney function in patients with RC. The most common methods used are the MDRD $(12,14,18), \operatorname{CKD}-\operatorname{EPI}(10,11)$ and isotopic $(5,18)$ methods. These equations represent a practical way to measure kidney function, which is reliable, easy to use and reproducible. The gold standard to measure the GFR is the use of isotopes or inulin; these methods are costly and not widely available in clinical practice. There are reports that suggest that methods like MDRD and CKD-EPI overestimate the GFR comparing this with isotopic methods (18) in patients post RC. Therefore, the differences between these series can be explained by variations in patient selection and the variety of methods used to calculate the eGFR.

The use estimated methods to assess the kidney function have some caveats and considerations. One important consideration is that these equations are dependent of the level of creatinine; this can be modified for a decreased or increase in the kidney function, but can also be affected by muscle mass, weight, diet, exercise and other possible factors $(28,29)$. A decrease in weight after diagnosis of cancer is a frequent phenomenon, Meyerhardt et al, previously reported a decrease in $37.5 \%$ of patients (30). On the other hand, it is unclear whether there is significant reabsorption of urea and creatinine in ICD patients, as the contact time of urine is shorter and the reabsorbing surface of an ICD is small. Animal models suggest that much of the creatinine is reabsorbed by solvent drag, a glucose-dependent way of transport. Creatinine is reabsorbed less well by an active carrier mediated transport. As urine normally does not have large amounts of glucose, creatinine may be resorbed to a lesser degree (31).

It should be noted that changes in renal function were not uniform across patients, in our analysis we showed that $36.7 \%$ of our patients has stable or mild increase in their eGFR, and $10.6 \%$ an increase $>10 \%$, previous reports showed similar findings Rouanne (12) et al 26\%, Gondo (10) et al 56\%. The presence of urinary obstruction (5) clinical or subclinical can affect the kidney function, therefore, once release of the ureteral obstruction happen after the RC, the kidney function will often improve $(5,10)$.

Our study showed cumulative incidence of dialysis of $5.6 \%$ at 5 years; Jin et al (14), report only $1.2 \%$ and Rouanne (12) et al 2.5\%. The low incidence in the Jin (14) et al report may be related to a younger population patient selection, exclusion criteria. Additionally, the incidence of dialysis may be affected by high mortality; also, because there is a higher incidence of comorbidity, the decision for conservative treatment may have been made.

The long-term renal function after RC can be adversely affected by several factors, including age, potential nephrotoxic chemotherapy, comorbidities, and diversion-related factors. Our results are 
concordant with previous studies, in that age and preoperative eGFR are associated significantly with postoperative renal function on both univariate and multivariate analyses $(11,12,32)$. However, there is not a clear consensus about other risk factors; neither chronic hypertension nor diabetes mellitus were associated with the decline eGFR $(10,12,19,32)$, or different types of ureterointestinal anastomoses, such as Bricker versus Wallace $(12,32)$ and urinary infection (12), chemotherapy $(19,32)$; nonetheless, other reports have shown association with $\operatorname{HTN}(5,11,14)$, Diabetes $(14)$, hydronephrosis post RC (11), urinary infection $(5,11,14)$ or total subcutaneous fat $(10)$.

The mortality at 10 years in the different cohorts was from 59 to $65 \%(12,14)$ in our study was $76.5 \%$. After adjustment in multivariate analysis the main risk factors associated were age, eGFR pre operative and sex. The lack of association with previous well-known risk factors like HTN or DM are most likely related to the follow up, the nature of the cancer and a high mortality rate, that have a high impact as a competitive event.

The present study is limited by its retrospective nature, nonrandomized design and it single institution study design may be associated with unknown biases. Additionally, we could not include well-known other clinical factors such as nutrition condition due to unavailability of data; excluding who did not have complete data available may have introduced selection bias. Despite these limitations, we have analysed a significant number of patients, with regular follow up, and we confirmed the live status, mortality and dialysis status with the National Cancer Centre Office and the National Renal Registry databases which are regularly updated and maintained prospectively. We did not evaluate the gold standard measures of inulin clearance or use of isotopes, we recognize the potentially limited accuracy of measuring serum creatinine in our patients, but the use of the eGFR is the common general practice, due to simplicity, cost and availability, and the eGFR is mainly used for management and therapeutic approach in practice.

\section{Conclusions}

In conclusion, our study suggest that there are a high proportion of patients with a RC and ileal conduit that have some degree of baseline renal impairment and will likely to deteriorate in the post-operative period; the preoperative eGFR and age, correlated significantly with early postoperative renal function deterioration, dialysis and mortality. Therefore, it is critical that from time of diagnosis these patients are optimised as their preoperative eGFR may dictate decisions about chemotherapy agent, their likelihood of requiring dialysis and their survival and follow-up of postoperative renal function is critical for long-term morbidity and mortality. Finally, further investigation by well-designed prospective studies is necessary to assess the changes of postoperative renal function decline in patients with bladder cancer.

\section{Declarations}

\section{Ethics approval and consent to participate.}

The present study was submitted to the ethical committee of the Beaumont Hospital and was approved. 


\section{Consent for publication.}

Not applicable.

\section{Availability of data materials.}

The datasets used and/or analysed during the current study are available from the corresponding author on reasonable request.

\section{Competing interests.}

All authors confirm that they have no conflicts of interest related to this research and the results presented in this paper have not been published previously in whole or part, except in abstract format.

\section{Funding.}

This study has no external support and was totally done with own resources.

\section{Authors' Contributions.}

Research idea and study design: JCH, PC; data acquisition: MH, CC, HO'S, SD; data analysis/interpretation: JCH, CE, PC, DL, MH; statistical analysis: JCH; supervision or mentorship: DL, PC.

Each author contributed important intellectual content during manuscript drafting or revision and accepts accountability for the overall work by ensuring that questions pertaining to the accuracy or integrity of any portion of the work are appropriately investigated and resolved.

\section{Acknowledgements.}

We gratefully acknowledge the contributions of the archive service staff, data managers from Beaumont Hospital and the National Cancer Registry of Ireland for providing us with access to the databases and especially to all the patients that are reflected in this research. 


\section{Financial Disclosure.}

The authors declare that they have no relevant financial interests, and we didn't receive at any time any payment or services from a third party (government, commercial, private foundation, etc.) for any aspect of the submitted work.

\section{References}

1. Stenzl A, Cowan NC, De Santis M, Kuczyk MA, Merseburger AS, Ribal MJ, et al. Treatment of Muscleinvasive and Metastatic Bladder Cancer: Update of the EAU Guidelines. Eur Urol. 2011 Jun 1;59(6):1009-18.

2. Kassouf W, Hautmann RE, Bochner BH, Lerner SP, Colombo R, Zlotta A, et al. A Critical Analysis of Orthotopic Bladder Substitutes in Adult Patients with Bladder Cancer: Is There a Perfect Solution? Eur Urol. 2010 Sep;58(3):374-83.

3. Shabsigh A, Korets R, Vora KC, Brooks CM, Cronin AM, Savage C, et al. Defining Early Morbidity of Radical Cystectomy for Patients with Bladder Cancer Using a Standardized Reporting Methodology. Eur Urol. 2009 Jan;55(1):164-76.

4. Shimko MS, Tollefson MK, Umbreit EC, Farmer SA, Blute ML, Frank I. Long-term complications of conduit urinary diversion. J Urol. 2011 Feb;185(2):562-7.

5. Samuel Joanne D, Bhatt Rupesh I, Montague Richard J, Clarke Noel W, Ramani Vijay AC. The Natural History of Postoperative Renal Function in Patients Undergoing lleal Conduit Diversion for Cancer Measured Using Serial Isotopic Glomerular Filtration Rate and 99mTechnetiumMercaptoacetyltriglycine Renography. J Urol. 2006 Dec;176(6)(1):2518-22.

6. Madersbacher S, Schmidt J, Eberle JM, Thoeny HC, Burkhard F, Hochreiter W, et al. Long-term outcome of ileal conduit diversion. J Urol. 2003 Mar;169(3):985-90.

7. Hautmann RE, de Petriconi RC, Volkmer BG. 25 Years of Experience With 1,000 Neobladders: LongTerm Complications. J Urol. 2011 Jun;185(6):2207-12.

8. Baber U, Gutierrez OM, Levitan EB, Warnock DG, Farkouh ME, Tonelli M, et al. Risk for recurrent coronary heart disease and all-cause mortality among individuals with chronic kidney disease compared with diabetes mellitus, metabolic syndrome, and cigarette smokers. Am Heart J. 2013 Aug;166(2):373-80.e2.

9. de Jager DJ, Vervloet MG, Dekker FW. Noncardiovascular mortality in CKD: an epidemiological perspective. Nat Rev Nephrol. 2014 Apr;10(4):208-14.

10. Gondo T, Ohno Y, Nakashima J, Hashimoto T, Nakagami Y, Tachibana M. Preoperative determinant of early postoperative renal function following radical cystectomy and intestinal urinary diversion. Int Urol Nephrol. 2017 Feb;49(2):233-8.

11. Eisenberg Manuel S, Thompson R, Houston F, Igor, Kim Simon P, Cotter Katherine J, Tollefson Matthew K, et al. Long-Term Renal Function Outcomes after Radical Cystectomy. J Urol. 2014 Mar 1;191(3):619-25. 
12. Rouanne M, Perreaud A, Letang N, Yonneau L, Neuzillet Y, Hervé J-M, et al. Trends in Renal Function After Radical Cystectomy and Ileal Conduit Diversion: New Insights Regarding Estimated Glomerular Filtration Rate Variations. Clin Genitourin Cancer. 2015 Jun;13(3):e139-44.

13. Nishikawa $M$, Miyake $H$, Yamashita $M$, Inoue T, Fujisawa $M$. Long-term changes in renal function outcomes following radical cystectomy and urinary diversion. Int J Clin Oncol. 2014 Dec;19(6) (1):1105-11.

14. Jin X-D, Roethlisberger S, Burkhard FC, Birkhaeuser F, Thoeny HC, Studer UE. Long-term Renal Function After Urinary Diversion by Ileal Conduit or Orthotopic lleal Bladder Substitution. Eur Urol. 2012 Mar 1;61(3):491-7.

15. Osawa T, Shinohara N, Maruyama S, Oba K, Abe T, Maru S, et al. Long-term renal function outcomes in bladder cancer after radical cystectomy. Urol J. 2013;10(1):784-9.

16. Ku JH, Lerner SP. Variables Affecting Long-term Maintenance of Renal Function Following lleal Based Urinary Diversion. Eur Urol. 2012 Mar 1;61(3):498-500.

17. Levey AS, Stevens LA. Estimating GFR, Using the CKD Epidemiology Collaboration (CKD-EPI). Creatinine Equation: More Accurate GFR Estimates, Lower CKD Prevalence Estimates, and Better Risk Predictions. Am J Kidney Dis Off J Natl Kidney Found. 2010 Apr;55(4):622-7.

18. Robinson R, Tait CD, Somov P, Lau MW, Sangar VK, Ramani VAC, et al. Estimated glomerular filtration rate is unreliable in detecting renal function loss during follow-up after cystectomy and urinary diversion. Int Urol Nephrol. 2016 Apr 1;48(4):511-5.

19. Makino K, Nakagawa T, Kanatani A, Kawai T, Taguchi S, Otsuka M, et al. Biphasic decline in renal function after radical cystectomy with urinary diversion. Int J Clin Oncol. 2017 Apr 1;22(2):359-65.

20. Gershman B, Eisenberg MS, Thompson RH, Frank I, Kaushik D, Tarrell R, et al. Comparative impact of continent and incontinent urinary diversion on long-term renal function after radical cystectomy in patients with preoperative chronic kidney disease 2 and chronic kidney disease 3a. Int J Urol. 2015;22(7):651-6.

21. Derose SF, Rutkowski MP, Crooks PW, Shi JM, Wang JQ, Kalantar-Zadeh K, et al. Racial Differences in Estimated GFR Decline, ESRD, and Mortality in an Integrated Health System. Am J Kidney Dis. 2013 Aug 1;62(2):236-44.

22. Peralta CA, Katz R, DeBoer I, Ix J, Sarnak M, Kramer H, et al. Racial and Ethnic Differences in Kidney Function Decline among Persons without Chronic Kidney Disease. J Am Soc Nephrol. 2011 Jul 1;22(7):1327-34.

23. Granerus G, Aurell M. Reference values for $51 \mathrm{Cr}$-EDTA clearance as a measure of glomerular filtration rate. Scand J Clin Lab Invest. 1981 Jan 1;41(6):611-6.

24. Davies DF, Shock NW. The variability of measurement of inulin and Diodrast tests of kidney function. J Clin Invest. 1950 May;29(5):491-5.

25. Rowe JW, Andres R, Tobin JD, Norris AH, Shock NW. The Effect of Age on Creatinine Clearance in Men: A Cross-sectional and Longitudinal Study. J Gerontol. 1976 Mar;31(2)(1):155-63. 
26. Warren B, Rebholz CM, Sang Y, Lee AK, Coresh J, Selvin E, et al. Diabetes and Trajectories of Estimated Glomerular Filtration Rate: A Prospective Cohort Analysis of the Atherosclerosis Risk in Communities Study. Diabetes Care. 2018 Aug 1;41(8):1646-53.

27. Vistisen D, Andersen GS, Hulman A, Persson F, Rossing P, Jørgensen ME. Progressive Decline in Estimated Glomerular Filtration Rate in Patients With Diabetes After Moderate Loss in Kidney Function-Even Without Albuminuria. Diabetes Care. 2019 Oct 1;42(10):1886-94.

28. Stevens LA, Coresh J, Greene T, Levey AS. Assessing Kidney Function - Measured and Estimated Glomerular Filtration Rate. N Engl J Med. 2006 Jun;8(23):2473-83. 354(.

29. Samra M, Abcar AC. False Estimates of Elevated Creatinine. Perm J. 2012;16(2):51-2.

30. Meyerhardt JA, Kroenke CH, Prado CM, Kwan ML, Castillo A, Weltzien E, et al. Association of Weight Change after Colorectal Cancer Diagnosis and Outcomes in the Kaiser Permanente Northern California Population. Cancer Epidemiol Biomark Prev Publ Am Assoc Cancer Res Cosponsored Am Soc Prev Oncol. 2017;26(1):30-7.

31. Pappenheimer JR. Paracellular intestinal absorption of glucose, creatinine, and mannitol in normal animals: relation to body size. Am J Physiol. 1990 Aug;259(2 Pt 1):G290-9.

32. Hatakeyama S, Koie T, Narita T, Hosogoe S, Yamamoto H, Tobisawa Y, et al. Renal Function Outcomes and Risk Factors for Risk Factors for Stage 3B Chronic Kidney Disease after Urinary Diversion in Patients with Muscle Invasive Bladder Cancer. PLOS ONE. 2016 Feb;22(2):e0149544. 11 .

\section{Tables}

Table 1. General characteristics. 


\begin{tabular}{|c|c|}
\hline Variable & Median (Range) \\
\hline Age (years) & $68.3(28.2-86.3)$ \\
\hline Weight (Kg) & $74(42-135)$ \\
\hline Height (cm) & $170(146-189)$ \\
\hline BMI $\left(\mathrm{kg} / \mathrm{m}^{2}\right)$ & $25.2(15.1-51.4)$ \\
\hline Time to death (years) & $4.6(0.5-22.1)$ \\
\hline Time to dialysis (years) & $3.3(0.03-17.4)$ \\
\hline eGFR pre surgery $\left(\mathrm{ml} / \mathrm{min} / 1.73 \mathrm{~m}^{2}\right)$ & $65.8(5.3-132.4)$ \\
\hline eGFR at 2 years $\left(\mathrm{ml} / \mathrm{min} / 1.73 \mathrm{~m}^{2}\right)$ & $58.2(5.1-117.8)$ \\
\hline Sex (male) \% & 73.7 \\
\hline \multicolumn{2}{|l|}{ Comorbidities \% } \\
\hline Diabetes & 14.7 \\
\hline Hypertension & 44.2 \\
\hline IHD & 29.3 \\
\hline CVA & 9.0 \\
\hline PVD & 18.5 \\
\hline \multicolumn{2}{|l|}{ Smoker \% } \\
\hline Current & 30 \\
\hline Ex smoker & 43.9 \\
\hline Chemotherapy \% & 23.5 \\
\hline \multicolumn{2}{|l|}{ Indication for surgery $\%$} \\
\hline Bladder cancer & 93.3 \\
\hline Other & 6.7 \\
\hline \multicolumn{2}{|l|}{ Surgical technique \% } \\
\hline Wallace & 29.8 \\
\hline Bricker & 64 \\
\hline Other & 6.2 \\
\hline \multicolumn{2}{|l|}{ Pathology stage \% } \\
\hline $\mathrm{T} \geq 2$ & 75.1 \\
\hline$N \geq 1$ & 47.6 \\
\hline$M=1$ & 28 \\
\hline
\end{tabular}

Table 02. Analysis of risk factors for mortality and ESKD. 


\begin{tabular}{|lcccc|}
\hline Variables & ESKD & sig & Mortality & sig \\
\hline & OR (CI 95\%) & $\mathrm{p}$ & OR (CI 95\%) & $\mathrm{p}$ \\
\hline Age (years) & $1.64(1.02-1.12)$ & 0.01 & $0.94(0.92-0.97)$ & 0.001 \\
\hline BMI (kg/m $\mathbf{2})$ & $0.90(0.79-1.03)$ & 0.11 & $1.04(0.97-1.12)$ & 0.30 \\
\hline eGFR pre-operative & $1.02(1.00-1.10)$ & 0.07 & $0.99(0.98-1.00)$ & 0.27 \\
\hline Sex (Male/Female) & $4.9(0.6-38.2)$ & 0.09 & $2.0(1.2-3.5)$ & 0.01 \\
\hline Diabetes & $1.8(0.5-6.9)$ & 0.38 & $1.7(0.8-3.6)$ & 0.19 \\
\hline Hypertension & $2.1(0.7-6.6)$ & 0.20 & $1.3(0.8-2.3)$ & 0.26 \\
\hline IHD & $1.5(0.5-4.9)$ & 0.46 & $1.7(0.9-3.0)$ & 0.08 \\
\hline CVA & $0.8(0.1-6.7)$ & 0.86 & $1.0(0.4-2.4)$ & 1.00 \\
\hline PVD & $0.3(0.1-2.7)$ & 0.30 & $1.1(0.5-2.0)$ & 0.87 \\
\hline Smoke & $3.8(0.5-30.1)$ & 0.30 & $1.6(0.9-2.9)$ & 0.14 \\
\hline Indication (cancer) & $1.4(0.2-11.5)$ & 1.00 & $10.1(3.4-30.2)$ & 0.001 \\
\hline Chemotherapy & $2.1(0.7-6.8)$ & 0.19 & $1.2(0.6-2.2)$ & 0.57 \\
\hline Surgical Technique & $0.9(0.9-1.0)$ & 1.00 & $0.8(0.4-1.9)$ & 0.65 \\
\hline TNM T $\geq 2$ & $3.4(1.2-10.3)$ & 0.05 & $2.3(1.3-4.2)$ & 0.007 \\
\hline TNM N $\geq 1$ & $2.2(0.6-8.7)$ & 0.34 & $1.1(0.6-1.9)$ & 0.79 \\
\hline TMN M=1 & $0.6(0.1-2.8)$ & 0.69 & $0.7(0.3-1.4)$ & 0.30 \\
\hline
\end{tabular}

Table 03. Logistic regression analysis for ESKD risk factors.

\begin{tabular}{|lcccccc|}
\hline \multicolumn{1}{|c}{ Variable } & B & S.E. & Sig & Exp (B) & CI95\% LL & CI95\% UL \\
\hline Age (years) & 0.12 & 0.04 & 0.001 & 1.13 & 1.05 & 1.22 \\
\hline eGFR pre operative & 0.04 & 0.01 & 0.008 & 1.04 & 1.01 & 1.07 \\
\hline Sex (male) & 2.53 & 1.51 & 0.09 & 12.5 & 0.64 & 243.5 \\
\hline Tumour T $\geq 2$ & 1.31 & 0.81 & 0.11 & 3.70 & 0.76 & 18.0 \\
\hline
\end{tabular}

Table 04. Logistic regression analysis for mortality risk factors.

\begin{tabular}{|lcccccc|}
\hline Variable & B & S.E. & Sig & Exp (B) & CI95\% LL & CI95\% UL \\
\hline Sex (male) & 2.7 & 1.31 & 0.04 & 14.8 & 1.1 & 192.5 \\
\hline Age (years) & 0.1 & 0.03 & 0.002 & 1.11 & 1.04 & 1.18 \\
\hline eGFR pre operative & 0.03 & 3.04 & 0.01 & 1.03 & 1.01 & 1.06 \\
\hline
\end{tabular}

\section{Figures}




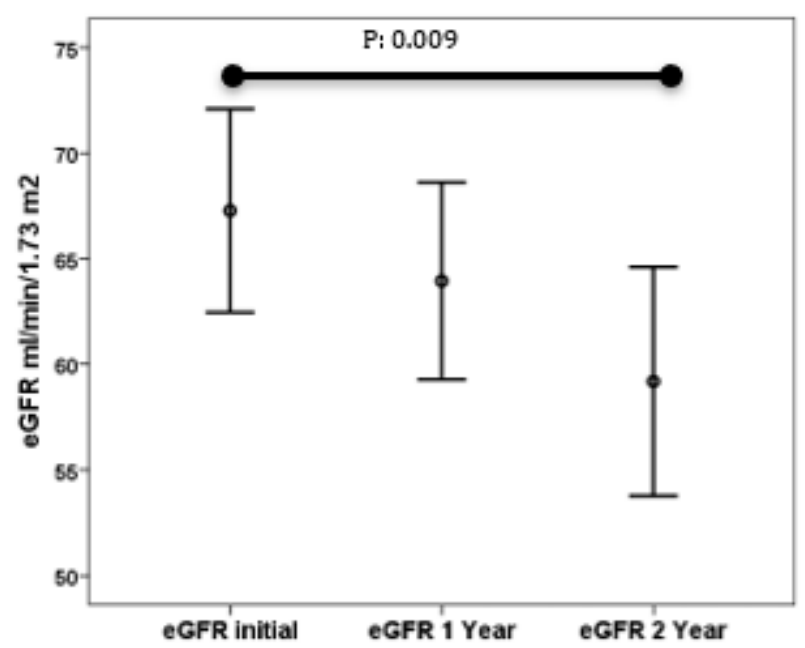

Figure 1

Renal function change after two years

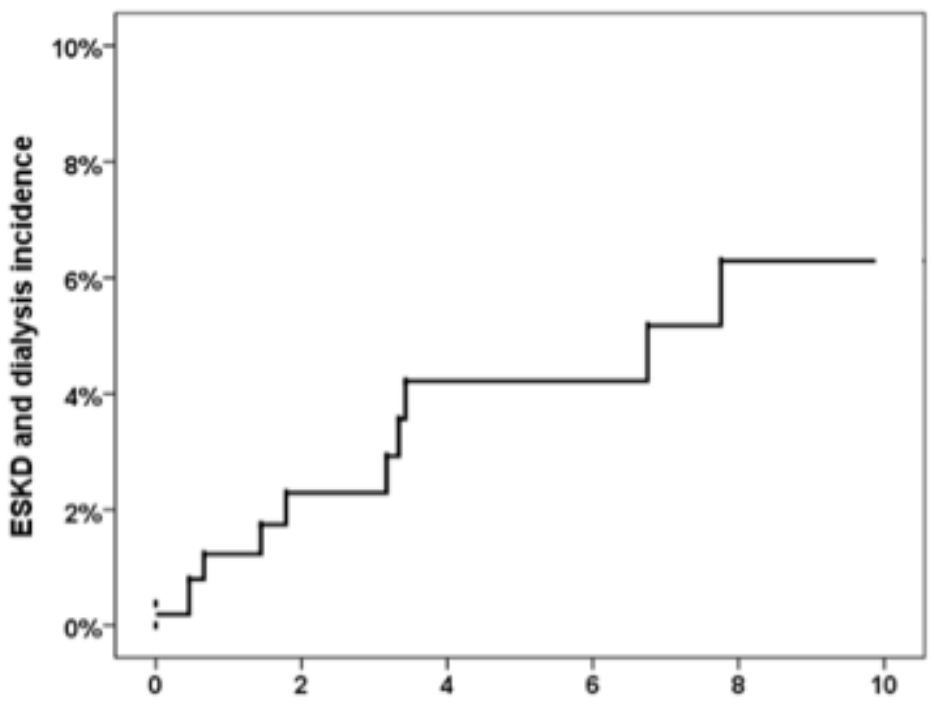

Figure 2

Cumulative percentage of ESKD incidence. 